\title{
ELECTROENCEPHALOGRAPHIC AND EYE MOVEMENT PATTERNS DURING SLEEP IN CHRONIC SCHIZOPHRENIC PATIENTS ${ }^{1}$
}

\author{
Donald F. Caldwell, Ph.D. and Edward F. Domino, M.D. \\ Division of Psychobiology, Lafayette Clinic, Detroit, Mich. \\ and Department of Pharmacology, University of Michigan, Ann Arbor, Mich. \\ (U.S.A.)
}

(Accepted for publication: November 17, 1966)

\section{INTRODUCTION}

Recent research has dealt with attempts to determine the possible presence of components unique to the EEG sleep patterns of psychotic patients. Liberson $(1944,1945)$ failed to discover significant abnormalities in the EEG sleep patterns of psychiatric patients, whereas DiazGuerrero et al. (1946), Lyketsos et al. (1953) and Hawkins et al. (1966) reported a significant increase in low voltage fast activity in psychotic patients. Gresham et al. (1965) observed a reduction in stage IV sleep for a group of depressed patients when compared to normal controls although this difference largely disappeared following improvement with therapy. Discovery by Aserinsky and Kleitman $(1953,1955)$ and Dement and Kleitman (1957a, b) of a low voltage fast EEG with accompanying rapid eye movements (viz., stage I-REM) which correlated with the subjective experience of dreaming, lead to an extensive study of this phenomenon in psychotic patients. In part, this interest derives from the opinions of many that dreams and hallucinations or, more broadly, psychotic behavior, may have a common underlying neural source. To date, schizophrenia has been the focus of much of this research and attempts to differentiate schizophrenic patients from non-schizophrenic or normal subjects for this sleep pattern have failed (Dement 1955; Koresko et al. 1963; Feinberg et al. 1964, 1965).

The present research was designed to investi-

\footnotetext{
1 This research is supported in part by U.S.P.H.S. Grant IR10 MH 11846-01A1
}

gate the EEG sleep stages during 5 consecutive uninterrupted nights of sleep in a group of adult schizophrenic male patients and reports the results of analyses completed to date for the second night.

\section{METHOD AND MATERIAL}

The criteria for diagnosis of chronic schizophrenia in the 25 male patients used in this study have been described by Crandall et al. (1966). All patients were from Northville State Hospital and housed in a special research ward until that time when they were transferred to the Lafayette Clinic 2 days prior to testing. At all times patients received a controlled adequate diet and daily vitamin supplements, received daily exercise, were in good physical health and were free of any abnormal neurological signs. All patients were free of drugs for a minimal period of 2 years with the exception of moderate daily amounts of coffee and cigarettes. Duration of hospitalization ranged from 6 to 17 years. The average age of patients was 32.8 years.

Normal control subjects $(N=10)$ were sophomore and junior year medical student volunteers in good physical health with a mean age of 24.3 years. All subjects were instructed to reduce their use of cigarettes and coffee during the tenure of the study and to refrain from them totally $6 \mathrm{~h}$ prior to their arrival to the laboratory for testing.

Continuous all night EEG recordings, electrooculograms (EOG) and EMGs were made on each subject for 5 consecutive nights from 11 p.m. to 6 a.m. Testing was conducted in an

Electroenceph. clin. Neurophysiol., 1967, 22: 414-420 
electrostatically shielded, sound-proofed, airconditioned room with recording equipment housed in adjacent quarters.

The International 10-20 System was used for unilateral electrode placement at the following loci: $F_{3}, C_{3}$, and $\mathrm{O}_{1}$; both earlobes wired in parallel serving as reference. Disc electrodes were attached to the left mastoid process for patient ground. Beckman biopotential skin electrodes were attached to the outer canthus of each eye, the mentalis muscle at the floor of the chin, and the digastric muscles immediately lateral to either side of the mentalis placement.

A 6-channel Grass model 7 polygraph was used, fitted with one model 7P1 low level DC preamplifier for eye movement recordings, and five model 7P5 wide band AC EEG pre-amplifiers with a $0.24 \mathrm{sec}$ time constant were used for all recordings. The polygraph ran continuously during the sleep period at $15 \mathrm{~mm} / \mathrm{sec}$. An experimenter was in constant attendance. Data from all channels were simultaneously recorded on magnetic tape (Mnemotron model 700-1400).

The scoring procedure utilized for all EEG sleep tracings consisted of marking the record into 1 min epochs and applying the criteria suggested by Williams et al. (1964) with the exception that stage 0 was omitted from the present analysis and a modification of the I-REM criterion was used (viz., stage I-REM was defined as a stage I EEG plus evidence of rapid eye movements and was scored from the first stage I containing an eye movement of at least $75 \mu \mathrm{V}$ amplitude; if during a period of stage I-REM a momentary absence of REM occurred in the continued presence of stage I exceeding $20 \mathrm{sec}$ minimal duration it was scored as stage I). Each record was scored by at least 2 of 3 independent raters. Where discrepancies occurred between raters, the record was scored by the third rater.

\section{RESULTS}

Since any comparison of sleep patterns between schizophrenic and normal control subjects rests strongly on the reliability of the control data, a statistical comparison of the sleep stages for controls in this study was made with those reported for a comparable group by Williams et al. (1964) using the scoring criteria described above. For only the I-REM data was the mean per cent value $(19.67 \%)$ significantly different $(P<0.01$; mean $=24.11 \%$, Williams et al. $)$. Since the two studies differed in the handling of stage I during a period of I-REM and the amplitude of acceptable eye movement, this difference may, in part, be related to differences in scoring technique. The values for per cent stage I-REM in the present investigation are, however, comparable to those (i.e., $19.40 \%$ ) reported by Dement (1960), for a similar age group of normal males.

Tables I and II present the percentage of total sleep time spent in each of the 5 stages of sleep for the second night for schizophrenic and control subjects, respectively. Statistical analyses computed between groups for mean percentage of each sleep stage revealed that only for stage IV was the difference significant (Mann-

\section{TABLE I}

Mean percentage of total second night sleep time for five stages of sleep for chronic schizophrenic patients

\begin{tabular}{lrrrrr}
\hline \multirow{2}{*}{$\begin{array}{c}\text { Schizophenic } \\
\text { subjects* }\end{array}$} & \multicolumn{5}{c}{ Percent sleep stage } \\
\cline { 2 - 6 } & \multicolumn{1}{c}{ I } & \multicolumn{1}{c}{ II } & \multicolumn{1}{c}{ III } & \multicolumn{1}{c}{ IV } & I-REM \\
\hline RC & 1.33 & 66.33 & 6.33 & 10.33 & 12.33 \\
WH & 4.92 & 47.54 & 12.79 & 22.30 & 12.46 \\
JA1 & 0.25 & 40.55 & 13.93 & 20.65 & 24.63 \\
SK & 3.23 & 59.68 & 12.63 & 12.63 & 11.83 \\
GT & 0.53 & 51.19 & 8.75 & 11.94 & 27.59 \\
RM & 3.17 & 47.07 & 17.80 & 6.34 & 25.61 \\
GW & 0.31 & 36.36 & 15.67 & 28.53 & 19.12 \\
RS & 1.60 & 64.97 & 8.82 & 0.53 & 24.06 \\
SW & 8.36 & 56.42 & 12.84 & 0.00 & 22.39 \\
RK & 3.23 & 43.87 & 10.97 & 20.32 & 21.61 \\
WK & 24.05 & 56.96 & 2.85 & 0.00 & 16.14 \\
ND & 8.41 & 44.01 & 15.21 & 8.74 & 23.62 \\
JG & 16.67 & 45.06 & 5.56 & 13.89 & 18.83 \\
MP & 7.56 & 39.24 & 14.24 & 20.93 & 18.02 \\
JA & 6.53 & 64.09 & 5.04 & 0.00 & 24.33 \\
JB & 3.77 & 78.26 & 1.16 & 0.00 & 16.81 \\
AH & 16.16 & 47.60 & 12.66 & 15.72 & 7.82 \\
HL & 7.01 & 67.39 & 0.27 & 0.00 & 25.34 \\
RL & 25.10 & 52.19 & 6.77 & 0.00 & 15.94 \\
JS & 3.32 & 47.23 & 18.82 & 8.12 & 22.51 \\
EK & 8.57 & 78.86 & 1.43 & 0.00 & 17.14 \\
JC & 33.83 & 46.71 & 6.29 & 5.99 & 7.19 \\
RP & 10.92 & 47.60 & 14.41 & 0.00 & 27.07 \\
FY & 3.37 & 66.87 & 16.56 & 0.00 & 13.19 \\
RG & 30.26 & 48.20 & 1.48 & 0.00 & 25.46 \\
Mean & 9.30 & 53.77 & 9.73 & 8.28 & 19.24 \\
\hline & & & & 5 & \\
\hline & & & & & \\
\hline
\end{tabular}

*Subjects are listed in the order of testing. 
TABLE II

Mean percentage of total second night sleep time for five stages of sleep for normal control subjects

\begin{tabular}{lrrrrr}
\hline $\begin{array}{l}\text { Control } \\
\text { subjects* }\end{array}$ & \multicolumn{6}{c}{ I } & \multicolumn{1}{c}{ II } & \multicolumn{1}{c}{ III } & \multicolumn{1}{c}{ IV } & I-REM \\
\cline { 2 - 6 } & \multicolumn{1}{c}{ I-Rent sleep stage } \\
RN & 5.64 & 51.54 & 7.44 & 11.03 & 24.36 \\
KK & 0.25 & 58.77 & 12.10 & 8.64 & 20.25 \\
DW & 3.82 & 51.76 & 6.18 & 19.41 & 18.82 \\
JC & 2.02 & 47.98 & 10.86 & 18.94 & 20.20 \\
LW & 7.02 & 40.45 & 8.43 & 24.72 & 19.38 \\
RL & 0.98 & 55.26 & 12.22 & 11.25 & 20.29 \\
SS & 4.67 & 64.29 & 8.79 & 4.12 & 18.13 \\
SC & 0.71 & 40.05 & 20.62 & 15.88 & 22.75 \\
JN & 2.82 & 52.54 & 9.89 & 20.06 & 14.69 \\
DB & 13.23 & 47.38 & 9.23 & 12.31 & 17.85 \\
Mean & 4.12 & 51.00 & 10.58 & 14.64 & 19.67
\end{tabular}

*Subjects are listed in order of testing.

Whitney $U=205.0 ; F=2.92, P=0.004)$. Inspection of Table $I$ reveals that ten of the 25 schizophrenic patients produced sleep records for which no stage IV could be scored. When these ten subjects were omitted from the analysis the mean per cent value for schizophrenic patients $($ mean $=13.80 \%$ ) did not differ statistically from the control group. Furthermore, although schizophrenic and control subjects did not statistically differ for mean percentage of stage III, the mean percentage of stage III for patients with stage IV absent (mean $=6.28$ ) was significantly less than for schizophrenics with stage IV (mean $=12.03, t=2.06, P<0.02$ ). Comparisons of these means to those for the control group were non-significant. Although these ten patients were not without occasional bursts of high voltage slow wave patterns, the latter were not sustained and did not fit the scoring criterion of stage IV. Furthermore, closer visual inspection of patient recordings revealed that for subjects manifesting stage IV the amplitude of the wave form was reduced relative to control subject records ${ }^{1}$. It appears that this finding exists only for the delta wave components of stages III and IV and is not indicative of a generalized attenuation of EEG voltages across all stages of sleep for the patients in this study.

\footnotetext{
1 This is presently being substantiated through the use of power density analyses and will be the subject of a later report.
}

The most outstanding feature was the near complete absence of any delta activity for approximately $40 \%$ of the schizophrenic patients tested. An investigation of sleep records for mean percentage stage IV for control and schizophrenic subjects for the fifth night of sleep has revealed no basic change from the second night values. This point has led us to further analyze the second night sleep data in terms of a subdivision within the schizophrenic population based on the presence or absence of stage IV.

The differences between schizophrenic patients (mean $=321.85 \mathrm{~min}$ ) and controls (mean $=$ $376.10 \mathrm{~min})$ in total time asleep was highly significant $(t=3.84, P<0.001)$. However, no difference was found between patients with stage IV present for either time asleep or age when compared to patients with stage IV absent (mean $=323.20 \mathrm{~min}$, and $32.6 \mathrm{yr}$ versus mean $=320.50 \mathrm{~min}$, and $33.1 \mathrm{yr}$, respectively). Furthermore, schizophrenic patients showed a significantly higher frequency of awakenings during the recording period (mean $=5.8$ ) than did the control subjects $($ mean $=2.8 ; t=2.86, P<0.01$ ). No differences were observed between patients grouped on the basis of presence or absence of stage IV for mean number of awakenings.

The mean time for the first occurrence of each stage of sleep from the onset of EEG recording is shown in Table III. Both patient groups required significantly longer time to attain stage I compared to controls reflecting the differences observed between groups of total time asleep. Furthermore, control subjects and patients with stage IV present attained stage III significantly earlier than patients without stage $1 \mathrm{~V}$, although schizophrenics with stage IV present were slower to manifest stage IV compared to controls. Measures of mean length of each sleep stage on initial occurrence revealed only the difference between patients (mean $=17.50 \mathrm{~min}$ ) and controls (mean $=31.60 \mathrm{~min}$ ) for stage IV to be significantly different $(t=2.21, P<0.05)$. It was interesting to note that roughly half of the patients with stage IV and control group subjects (viz., $53.3 \%$ and $40.0 \%$ for schizophrenic and control subjects, respectively) manifested a .hird period of stage IV of approximately equal duration (viz., $7.6 \mathrm{~min}$ and $10.8 \mathrm{~min}$ ). Similarly, between 20 and $30 \%$ of the subjects in each group 
TABLE III

Mean time ( $\mathrm{min}$ ) required for the first occurrence of each stage of sleep from beginning of EEG recording

\begin{tabular}{|c|c|c|c|c|c|}
\hline \multirow{2}{*}{ Subjects } & \multicolumn{5}{|c|}{ Sleep stages } \\
\hline & $\mathbf{I}$ & $\overline{\text { II }}$ & III & IV & I-REM \\
\hline $\begin{array}{l}\text { Schizophrenics } \\
\text { (stage IV present) } \\
\qquad N=15\end{array}$ & $21.6^{\mathrm{a}}$ & 31.4 & $38.6^{c}$ & $46.9 e$ & 93.1 \\
\hline $\begin{array}{l}\text { Schizophrenics } \\
\text { (stage IV absent) } \\
\qquad N=10\end{array}$ & $19.5^{b}$ & 29.2 & $85.9 c, d$ & - & 101.0 \\
\hline $\begin{array}{l}\text { Controls } \\
\qquad N=10\end{array}$ & $6.3^{\mathrm{a}, \mathrm{b}}$ & 15.3 & $26.9^{d}$ & $28.9 e$ & 88.3 \\
\hline
\end{tabular}

sDifference significant at $P<0.001$, two-tailed.

b,c, aDifference significant at $P<0.01$, two-tailed.

eDifference significant at $P<0.05$, two-tailed.

TABLE IV

Mean number of stage changes during hourly intervals

\begin{tabular}{|c|c|c|c|c|c|c|}
\hline \multirow{2}{*}{ Subjects } & \multicolumn{6}{|c|}{ Hourly intervals } \\
\hline & $1 \mathrm{st}$ & 2nd & $3 \mathrm{rd}$ & 4 th & 5 th & 6 th \\
\hline $\begin{array}{l}\text { Schizophrenics } \\
\text { (stage IV present) }\end{array}$ & $\begin{array}{l}13.3^{*} \\
(N=15)\end{array}$ & $\begin{array}{c}10.8 \\
(N=15)\end{array}$ & $\begin{array}{c}9.1 \\
(N=15)\end{array}$ & $\begin{array}{c}9.3 \\
(N=15)\end{array}$ & $\begin{array}{c}9.0 \\
(N=14)\end{array}$ & $\begin{array}{r}7.0 \\
(N=8)\end{array}$ \\
\hline Schizophrenics & $\begin{array}{c}11.9^{* *} \\
(N=10)\end{array}$ & $\begin{array}{c}8.1 \\
(N=10)\end{array}$ & $\begin{array}{c}10.1 \\
(N=10)\end{array}$ & $\begin{array}{c}8.4 \\
(N=10)\end{array}$ & $\begin{array}{r}8.8 \\
(N=9)\end{array}$ & $\begin{array}{r}4.3 \\
(N-3)\end{array}$ \\
\hline Controls & $\begin{array}{r}7.7^{* * * *} \\
(N=10)\end{array}$ & $\begin{array}{c}9.1 \\
(N=10)\end{array}$ & $\begin{array}{c}7.2 \\
(N=10)\end{array}$ & $\begin{array}{c}5.0 \\
(N=10)\end{array}$ & $\begin{array}{c}7.4 \\
(N=10)\end{array}$ & $\begin{array}{r}6.2 \\
(N=9)\end{array}$ \\
\hline
\end{tabular}

*Difference significant at $P<0.001$, two-tailed.

**Difference significant at $P<0.02$, two-tailed.

showed a fourth period of stage IV at approximately $248 \pm 10 \mathrm{~min}$ after the occurrence of the first stage I. There were no distinguishing differences between groups for either mean time of successive occurrences of I-REM periods following initial stage I onset or for period lengths.

Mean number of sleep stage changes for hourly intervals is presented in Table IV. During the first hour of recording both patient groups manifested a significantly larger number of stage changes than control subjects; thereafter group differences largely disappeared. Although neither patient group differed within hourly interval comparisons, the mean number of total changes for the entire night of recording was significantly larger for schizophrenics with stage IV present (mean $=9.7$ ) when compared to control subjects (mean $=7.1 ; t=2.50, P<0.05$ ). Mean total sleep stage changes for schizophrenics with stage IV absent (mean $=8.6$ ) did not differ statistically from either of the groups.

\section{DISCUSSION}

Data for stage I-REM represent a further verification of the well documented inability to differentiate schizophrenic patients and normals for this stage. However, the finding that $40 \%$ of the patients tested failed to manifest any scoratle stage IV and exhibited a significantly reduced amount of stage III is, to the present investigators, an heretofore unreported finding for a population of chronic schizophrenics.

Observed differences between schizophrenics and controls for mean time to occurrence of stage I (see Table III), number of first hour mean sleep stage changes (see Table IV), and 
initial length of first stage IV may be explained by the greater fluctuation between wakefulness, drowsiness, and sleep observed for schizophrenic patients during the early period of recording. It may be seen from an inspection of Table III that when time to reach first stage I (viz., time generally attributed to stage 0 ) is subtracted from time to reach stages III and IV for both patients with stage IV present (mean $=17.0$ and 25.3 for stages III and IV, respectively) and control subjects (mean $=20.6$ and 22.6 for stages III and IV, respectively) differences between these groups disappear. However, the time to achieve first stage III for patients with stage IV absent remains significantly longer (mean $=66.4)$ compared to the other groups even when pre-stage I activity is subtracted. The data for mean length of first occurrence of each sleep stage represent a measure largely independent of group differences in achieving sleep. These data, in combination with length of subsequent stage IV periods indicated that even for patients with stage IV present the amount of this activity was reduced relative to values for control subjects. It was noted earlier in this paper that reduced stage IV or, more appropriate high voltage slow activity, has been reported for psychotic depressed patients (Gresham et al. 1965 and Hawkins et al. 1966). By way of an indirect inference bearing on our finding is the report of Lyketsos et al. (1953) that schizophrenic subjects produced a higher incidence of abnormally fast EEG activity compared to other psychotic or control subjects, as well as a generalized lower voltage across all sleep patterns when compared only to normals.

The sharp contrast within the schizophrenic population evidenced by total absence of stage IV in $40 \%$ of the subjects is similar to the group differentiation reported by Domino and Caldwell (1966) for the effects of schizophrenic plasma on learning ability in the rat. The present data clearly indicate a failure of the brain of schizophrenics to achieve a high voltage, "slow wave" pattern, although the reason for such a failure to occur to a specific frequency band is difficult to explain. On the other hand, EEG studies have indicated "slow wave" sleep to be forebrain in origin (Akert et al. 1965 and Jouvet 1960), a region in all likelihood, implicated in the faulty thought processes observed in schizophrenic behavior. More recently, Oswald et al. (1966) have shown L-tryptophan, 5-10 g orally, taken prior to bedtime, in normal human subjects reduced the amount of slow wave activity normally present in the first hour of sleep. Tryptophan turnover studies would be of special interest in these schizophrenic patients.

Research showing a "make-up" effect for stage IV following deprivation of the EEG pattern (Agnew et al. 1964) implies a possible biological significance to the organism of this activity. Koranyi and Lehmann (1960), although presenting no pre-test data, reported that they did not observe the usual development of delta wave patterns in a group of six chronic schizophrenics following $52 \mathrm{~h}$ of sleep deprivation. The question of whether stage IV deficient patients could be forced into greater output of high voltage slow wave activity following prolonged sleep deprivation might contribute to further evaluation of our findings. Such a project is presently being conducted.

\section{SUMMARY}

Continuous all night sleep EEG recordings were obtained from a group of 25 chronic, hospitalized schizophrenic patients and ten normal control subjects for 5 consecutive nights. Analyses are presented for the second night of sleep. Results for mean percentage of stages I, II, III, IV and I-REM for control subjects were found to be similar to values reported for comparable control populations using similar scoring techniques. In contrast, $40 \%(N=10)$ of the schizophrenic patients failed to manifest any scorable stage IV and were significantly reduced in amount of stage III. For all patients, a reduction in amplitude of the delta wave component of stages III and IV was apparent relative to control subject records. Schizophrenic patients were found to have a more disturbed sleep compared to controls, although no distinction was apparent between patients with or without stage IV present. Differences in time of onset, duration, and number of sleep stage changes were noted between schizophrenic and control subjects. Possible implications arising from the observed disturbance of "slow wave" patterns in the sleep EEGs of schizophrenic patients are discussed in light of research on the loci of this 
activity in the brain, as well as recent reports linking amino acid levels and EEG sleep patterns.

\section{RÉSUMÉ}

\section{ÉLECTROENCÉPHALOGRAMME ET MOUVEMENTS OCULAIRES AU COURS DU SOMMEIL CHEZ DES MALADES SCHIZOPHRÈNES CHRONIQUES}

Les auteurs ont enregistré de façon continue le sommeil de nuit d'un groupe de 25 malades schizophrènes chroniques hospitalisés, et de dix sujets normaux de contrôle, pendant 5 nuits consécutives. Les résultats présentés concernent la seconde nuit de sommeil.

Le pourcentage moyen de stades I, II, III, IV et PMO trouvé chez les sujets de contrôle est similaire à ceux qui ont été rapportés dans des populations de contrôle comparables, lorsque des techniques identiques ont été utilisées. Par contre, $40 \%(N=10)$ des malades schizophrènes ne montrent aucun stade IV quantifiable, et un taux de stade III considérablement réduit. Pour tous les malades, une réduction d'amplitude des ondes lentes que comportent les stades III et IV est relevée, par rapport aux enregistrements des sujets normaux. Les schizophrènes ont un sommeil plus perturbé que les sujets de contrôle, bien qu'aucune distinction ne soit possible entre les malades avec et sans stade IV.

Des différences dans le moment de début, la durée et le nombre des cycles de sommeil sont notées entre schizophrènes et sujets de contrôle. Les hypothèses possibles que soulèvent les perturbations observées dans la forme des ondes lentes du sommeil électrique des schizophrènes sont discutées à la lumière des recherches sur le lieu d'origine de cette activité dans le cerveau, ainsi qu'à la lumière des études récentes qui relient le taux des acides aminés et l'EEG.

The authors wish to express their appreciation to the following project participants: P. G. S. Beckett, M.D., and E. Luby, M.D., for patient scheduling; J. Henke, B.S., D. Miller, B.S., J. Dunn, B.S., and D. Fitzgerald, R.N., for subject testıng and record scoring; and Miss M. K. Frost and Mrs. R. Henke for data analysis and preparation of this manuscript.

\section{REFERENCES}

Agnew JR., W. H., WebB, W. B. and Williams, R. L. The effects of stage four sleep deprivation. Electroenceph. clin. Neurophysiol., 1964, 17: 68-70.
Akert, K., Bally, C. and Schadé, J. P. (Eds.). Sleep mechanisms. Progress in Brain Research, Vol. 18. Elsevier, Amsterdam, 1965, 257 p.

ASERINSKy, E. and KLEITMAN, N. Regularly occurring periods of eye motility and concomitant phenomena during sleep. Science, 1953, 118: 273-274.

Asfrinsky, E. and Kleitman, N. Two types of ocular motility occurring in sleep. J. appl. Physiol., 1955, 8: $1-10$.

Crandall, R. G., Day, H., Beckett, P. G. S., Chen, C., Brosius, O. D. and Frohman, C. E. Conflicts between treatment and science on a research ward investigating schizophrenia. J. Canad. Psychiat. Ass., 1966, 4: 306-313.

Dement, W. Dream recall and eye movements during sleep in schizophrenics and normals. $J$. nerv. ment. Dis., 1955, 122: 263-269.

DemENT, W. The effect of dream deprivation. Science, 1960, 131: 1705-1707.

Dement, W. and Kleitman, N. The relation of eye movements during sleep and dream activity: an objective method for the study of dreaming. J. exp. Psychol., 1957a, 53: 339-346.

Dement, W. and Kleitman, N. Cyclic variations in BEG during sleep and their relation to eye movements, body motility, and dreaming. Electroenceph. clin. Neurophysiol., 1957b, 9:673-690.

Diaz-Guerrero, R., Gottlieb, J. S. and Knott, J. R. The sleep of patients with manic-depressive psychoses, depressive type. Psychosom. Med., 1946, 8: 399-404.

Domino, E. F. and CALdwell, D. F. The differential effects of plasma from two groups of clinically similar schizophrenic patients on learning behavior in rats. J. psychiat. Res., 1966, 4: 87-94.

FeinberG, 1., Koresko, R. L. and Gottlieb, F. Further observations on electrophysiological sleep patterns in schizophrenia. Comprehens. Psychiat., 1965, 6: 21-24.

Feinberg, I., Koresko, R. L., Gottlieb, F. and Wender, P. H. Sleep electroencephalographic and eye-movement patterns in schizophrenic patients. Comprehens. Psychiat., 1964, 5: 44-53.

Gresham, S. C., Agnew JR., H. W. and Williams, R. L. The sleep of depressed patients. Arch. gen. Psychiat., 1965, 13: 503-507.

Hawkins, D. R., Mendels. J., Scott, J., Bensch, G. and Teachey, W. Sleep in psychotic depression. Psychiat. Spectat., 1966, 3: 2.

JoUVET, M. Telencephalic and rhombencephalic sleep in the cat. In G. E. W. Wolstenholme and M. O'CONNOR (Eds.), The nature of sleep. Little, Brown and Co., Boston, Mass., 1960: 188-206.

Koranyi, E. K. and Lehmann, H. E. Experimental sleep deprivation in schizophrenic patients. Arch, gen. Psychiat., 1960, 2: 534-544.

Koresko, R. L., SNyder, F. and FeinberG, I. Dream time in hallucinating and non-hallucinating schizophrenic patients. Nature (Lond.), 1963, 199:1118-1119.

LIBERSON, W. T. Functional electroencephalography in mental disorders. Dis. nerv. Syst., 1944, 5: 357-364.

Liberson, W. T. Problems of sleep and mental disease. Digest Neurol. Psychiat., 1945, 13: 93-108.

Electroenceph. clin. Neurophysiol., 1967, 22: 414-420 
LyKeTSOS, G., Belinson, L. and GibBs, F. A. Electroencephalograms of non-epileptic psychotic patients awake and asleep. Arch. Neurol. (Chic.), 1953, 69: 707-712.

Oswald, I., Ashcroft, G. W., Berger, R. J., Eccleston,

D., Evans, J. I. and ThaCoRs, V. R. Some experiments in the chemistry of normal sleep. Brit. J. Psychiat., 1966, 112: 391-399.

Williams, R. L., Agnew JR., H. W. and Webr, W. B. Sleep patterns in young adults: an EEG study. Electroenceph. clin. Neurophysiol., 1964, 17: 376-381.

Rejerence: Caldwell, D. F. and Domino, E. F. Electroencephalographic and eye movement patterns during sleep in chronic schizophrenic patients. Electroenceph. clin. Neurophysiol., 1967, 22: 414-420. 